in the same sense. We have here, probably for the first time, quite unambiguous evidence for the existence of molecular electronic levels which are additional to the ordinary atomic system of levels. Such addi. tional levels constitute an important feature of Hund's recent theoretical work on band spectra. Briefly expressed, his view is that whereas in atoms the term type is determined by the total orbital angular momentum $(l)$ of the outer electrons, in molecules it is determined by the component $\left(i_{l}\right)$ of this parallel to the line of nuclei. Thus in atoms we have only one $S$ sequence $(l=0)$ of a given multiplicity, but in molecules more than one may exist, corresponding to $i_{l}=0(l=0,1,2 \ldots)$. The characteristics of the $X$ level, for example, strongly suggest that it is related to the $S$ level in some such way as this.

\section{W. E. Curtis.}

Armstrong College,

Newcastle-upon-Tyne.

\section{The Sligo Artefacts.}

For some years past, in my researches upon the Norfolk coast, I have made a close study of the alleged hurling of large flints against each other during storms, and as, after much observation, I have not seen such collisions take place, I am unable to believe in their occurrence in the area I have investigated. So far as my knowledge extends, the capability of waves in picking up stones is limited to comparatively small specimens. These, when they fall, may strike others lying upon the beach, but such impacts, especially as they occur in water-a medium which definitely lessens the force of the blow-cannot remove, in ordinary circumstances, flakes of large dimensions (see Science Progress, No. 87, Jan. 1928). It is known that stones of considerable size are sometimes thrown by the action of the sea on to promenades, but these stones are apparently being rolled towards the shore, and by the uprush of the water when it meets a more or less vertical sea-wall, are carried on to the promenade. There cannot, of course, be any doubt that bulky masses of flint are propelled up the beach, sometimes aided by the buoying effect of attached seaweed, and I have witnessed such movements while storms were in progress upon the east coast. But the travel of the flints is very gradual, as it is only certain waves which are capable of moving them, and the extent of each stage of advance is generally small.

I am not familiar with the capabilities of the Atlantic in moving blocks of limestone upon the Sligo coast, but, for the reasons mentioned above, I would regard it as improbable that masses of this rock of the size described by Profs. Jones and Boswell in Nature of June 2 could ever have been hurled to their present position by wave action. I can, however, imagine that such blocks could by slow degrees be transported by the sea to where they are now found. Actual observation during storms is what is needed for the elucidation of this question, and until this is carried out erroneous views regarding it may be prevalent.

Since Mr. Burchell's last letter to Nature he has again visited Sligo and found in situ in ancient deposits, two more artefacts. One of these, made of quartzite, is a remarkable specimen, which is, $\mathbf{I}$ imagine, sure to be enthusiastically received by those who, like myself, by reason of the evidence already to hand, believe in the greater antiquity of man in Ireland. The other specimens, found previously by Mr. Burchell in situ in boulder clay, are, in my opinion, clearly of human origin, and of very great importance.

\section{One House,}

J. ReID MoIr.

\section{A Voracious Pike.}

The photograph here reproduced (Fig. 1) shows the attitude of two pike as they were washed ashore dead in the lake here a few days ago. The smaller fish, weighing $7 \frac{1}{2} \mathrm{lb}$., had bitten off a good deal more than he could chew of the larger- $8 \mathrm{lb}$. I suppose the two fishes met head on, so that neither could discern the size of the other. The smaller fish, seeing some-

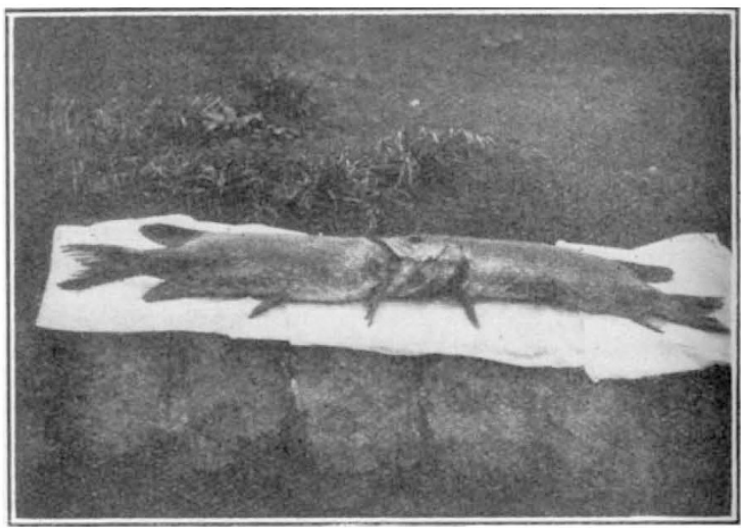

FIG. 1 .

thing that seemed edible before him, went for it and paid full penalty for its voracity. Several years ago the late Mr. Malloch, of Perth, sent me a photograph of two pike that had been washed ashore in Loch Tay in precisely the same posture as ours. If I remember aright, they weighed 8 or $9 \mathrm{lb}$. apiece.

\section{Herbert Maxweil.}

Monreith, Whauphill, Wigtonshire.

\section{Woods and Wireless.}

IN a letter in NaTURE of April 7, Dr. Rolf makes some very interesting comments on the subject of absorption of wireless waves by trees, and refers to a paper in which I directed attention to this phenomenon. It is quite clear, as Dr. Rolf points out, that the capacity effect of the tree ought to be taken into account as well as its conductivity effect. It appears to me, however, to be a little doubtful whether such a simple modification of Sommerfeld's theory as Dr. Rolf proposes, is all that is required. The constants of conductivity and S.I.C. employed by Sommerfeld are for an isotropic medium, whereas used in connexion with trees they refer only to the vertical axis. Again, if we increase the conductivity of the tree we clearly increase the energy absorbed, and therefore the attenuation will be greater, whereas by Dr. Rolf's method, an increase of the conductivity leads to the opposite conclusion.

Dr. Rolf seeks to explain by the capacity effect of trees the curious phenomenon of negative damping (which, by the way, was first discovered not by myself but by Messrs. Ratcliffe and Barnett), but I am inclined to doubt whether this is the cause in the case of the curve obtained for Daventry, since this region is one of comparatively few trees, and further, the departure of the attenuation from its ideal value (assuming a bare surface) has been found to be small. The explanation, however, should not be abandoned without further investigation.

Radio Research Station,

R. H. Barfiello.

Datchet, Windsor, May 16. 